\title{
La economía social y solidaria en el desarrollo local
}

\author{
The social and solidarity economy in local development
}

1 Santiago David Muñoz Solórzano Pontificia Universidad Católica del Ecuador sdmunoz@puce.edu.ec

2 Betty Elizabeth Cueva Ochoa Universidad de las Fuerzas Armadas (ESPE) becueva@espe.edu.ec

3 Sandra Dayanín Suárez Rivera Universidad Central del Ecuador sdsuarezr@uce.edu.ec

4 María Cristina Gomezjurado Jarrín c_gomezjurado@hotmail.com https://orcid.org/0000-0001-6013-8413

https://orcid.org/0000-0003-3512-8111

https://orcid.org/0000-0002-4537-3447

https://orcid.org/0000-0002-9811-2232

Artículo de Investigación Científica y Tecnológica Enviado: $11 / 12 / 2021$

Revisado: $26 / 12 / 2021$

Aceptado: $18 / 01 / 2022$

Publicado:14/02/2022

DOI: $\underline{\text { https://doi.org/10.33262/ap.v4i1.2.172 }}$

Cítese: Muñoz Solórzano, S. D., Cueva Ochoa, B. E., Suárez Rivera, S. D., \& Gomezjurado Jarrín, M. C. . (2022). La economía social y solidaria en el desarrollo local. AlfaPublicaciones, 4(1.2), 21-34. https://doi.org/10.33262/ap.v4i1.2.172

ALFA PUBLICACIONES, es una Revista Multidisciplinar, Trimestral, que se publicará en soporte electrónico tiene como misión contribuir a la formación de profesionales competentes con visión humanística y crítica que sean capaces de exponer sus resultados investigativos y científicos en la misma medida que se promueva mediante su intervención cambios positivos en la sociedad. https://alfapublicaciones.com

La revista es editada por la Editorial Ciencia Digital (Editorial de prestigio registrada en la Cámara Ecuatoriana de Libro con No de Afiliación 663) www.celibro.org.ec 
Palabras

claves:

Economía

Social $\mathrm{y}$

Solidaria (ESS), desarrollo local, cooperativismo, sociedad mercantil, sector social de la economía.

\section{Keywords:}

Social and

Solidarity

Economy

(SSE), local development, corporativism, commercial

\section{Resumen}

Introducción. En este documento se busca definir la Economía Social y Solidaria desde la perspectiva local en el Ecuador, tomando en cuenta las diferentes entidades que intervienen en el desarrollo local. Se busca identificar mediante una metodología cualitativa las instituciones gubernamentales y no gubernamentales que intervienen en el desarrollo local, analizando el progreso que han tenido en el país y si su propósito opera dentro del mismo. Objetivo. Determinar los medios que usa la Economía Social y Solidaria (ESS) para alcanzar el desarrollo local a través de la movilización de adecuados recursos territoriales aplicados en la práctica consuetudinaria como respuesta a problemas de la sociedad actual. Metodología. A través de una metodología cualitativa, se busca analizar la aplicación de la Economía Social y Solidaria en el desarrollo local del país, ampliando la información referente a las cooperativas y su funcionamiento, sus tipos y su aportación económica al mercado local. Resultados. Mediante el análisis de las instituciones encargadas de la administración de la Economía Popular y Solidaria (EPS) y la capacitación de las personas dentro de este sector financiero, se pudo identificar que, debido a la ineficiencia de la coordinación y control de las organizaciones financiadas por la misma, la Economía Social y Solidaria en el país no potencializa resultados en pro del desarrollo local, pese a estar orientada a principios del buen vivir que buscan mejorar la calidad de vida de la población vulnerable. Conclusiones. La Economía Social y Solidaria, con un adecuado manejo y control, contribuirá exponencialmente al desarrollo local del país. Con un mayor enfoque social, y no meramente económico, se podría impulsar la creación de diferentes tipos de emprendimientos que generarían mayores réditos económicos en los sectores rurales del país.

\section{Abstract}

Introduction. This document seeks to define the social and solidarity economy from a local perspective in Ecuador, taking into account the different entities involved in local development. It seeks to identify through a qualitative methodology the governmental and non-governmental institution involved in local development, analyzing the progress they have made in the country and whether their purpose operates within it. Objective. To determine the means 
society, social sector of the economy.

\begin{abstract}
used by the social and solidarity economy (SSE) to achieve local development through the mobilization of adequate territorial resources applied in customary practice as a response to current societal problems. Methodology. Through a qualitative methodology, we seek to analyze the application of the social and solidarity economy in the local development of the country, expanding the information regarding cooperatives and their operation, their types and their economic contribution to the local market. Results. Through the analysis of the institutions in charge of the administration of the Popular and Solidarity Economy (EPS) and the training of people within this financial sector, it was possible to identify that, due to the inefficient coordination and control of the organizations financed by it, the social and solidarity economy in the country does not potentiate results in favor of local development, despite being oriented to principles of good living that seek to improve the quality of life of the vulnerable population. Conclusions. The social and solidarity economy, with proper management and control, will contribute exponentially to the country's local development. With a greater social focus, and not merely economic, it could promote the creation of different types of enterprises that would generate greater economic returns in the rural sectors of the country.
\end{abstract}

\title{
Introducción
}

La Economía Social y Solidaria (ESS) se entiende como un modelo económico cuyo funcionamiento se basa en la productividad de la sociedad mediante la colaboración de factores económicos dentro del sistema. Para Coraggio (2011), la Economía Social y Solidaria (ESS) es un sistema económico cuyo funcionamiento asegura la base material integrada a una sociedad justa y equilibrada.

En otros términos, como explican Tapia y Alvarado (2019), la Economía Social y Solidaria, está explicada como un conjunto de iniciativas socioeconómicas, formales o informales, individuales o colectivas, que priorizan la satisfacción de las necesidades de las personas por encima del lucro.

Así también, en lo local la Economía Social y Solidaria (ESS) se enfoca en el mejoramiento de las condiciones de vida, desde una perspectiva interna de producción. A 
través de este enfoque de tipo social, la Economía Social y Solidaria (ESS) busca generar empleo con la creación de emprendimientos y cambios en la innovación social en el mercado.

En el contexto histórico, la Economía Social y Solidaria (ESS) tiene sus orígenes desde las primeras civilizaciones de la humanidad, como lo es la griega, la cual se fundamentaba en la ayuda mutua como motor de la economía. Años más tarde, después del cristianismo primitivo nace como una doctrina de vida comunitaria, hasta otras civilizaciones posteriores que tenían como modelo de economía social la ayuda comunitaria bajo los principios de Sócrates. Ya en tiempos modernos, en el siglo pasado, la Economía Social y Solidaria (durante tiempos de conflictos bélicos y guerras frías), surgiría como un modelo de igualdad, trabajo y democracia que se fundamentaría en las necesidades sociales y en el desarrollo del mercado (Villacrés et al., 2018).

En el Ecuador la Economía Social y Solidaria surge antes de la colonia, pero solo a partir de la Constitución de la República del Ecuador de 2008, los indígenas adquirieron mayor participación, misma que se mantiene hasta la actualidad. Gracias a los principios colectivos de los indígenas, y la influencia de la Economía Social y Solidaria (ESS) como "nuevo" modelo de economía en los países latinoamericanos, esta resurge en el país como un modelo económico capaz de afrontar la crisis financiera existente al momento.

En todo caso, a diferencia del modelo económico capitalista, en el que, el capital está por encima de los actores de producción, el modelo de la economía social se encamina a políticas económicas de desarrollo local, las cuales se enfocan en las PYMES (pequeña y mediana empresa), a través de las instituciones creadas por el estado para el apoyo a estas empresas con los recursos necesarios. En tal sentido, se podrían definir las razones por las que la Economía Social y Solidaria (ESS) funcionaría mejor en el desarrollo local de un país.

Para que la Economía Social y Solidaria sea implementada de manera adecuada según Tapia y Alvarado (2019), se requerirá de estos cinco principios:

Principio de Equidad: La equidad es un valor que reconoce a todas las personas como sujetos de igual dignidad.

Principio de Trabajo: El trabajo como elemento principal en la calidad de vida de las personas.

Principio de Sostenibilidad Ambiental: La pacífica relación con la Naturaleza es una fuente de riquezas económicas.

Principio de Cooperación: La colaboración de entidades públicas y privadas con el fin de fomentar las relaciones en red y la generación de sinergias. 
Principio de Compromiso con el Entorno: Participación de sociedad y estado para contribuir al desarrollo local con cooperación capital e industrial.

De acuerdo a los principios mencionados la Economía Social y Solidaria (ESS), se enfoca en dar solución a las necesidades básicas de los individuos dentro de una sociedad, con una perspectiva económica local de la misma, que también brinde un beneficio económico como la generación de empleo.

Tanto el enfoque social y el enfoque económico de la Economía Social y Solidaria (ESS), depende de una organización política y social para desarrollar la economía local, es decir, que en lo político deben existir entidades (públicas o privadas), que impulsen la aplicación de la Economía Social y Solidaria (ESS).

Por lo tanto, además de la colaboración de entidades creadas para el desarrollo local de la economía, también se requerirá de la innovación social para la creación de emprendimientos. La innovación social deberá ser importante para la población, ya que debe fomentar el trabajo y la recompensa de este, garantizando la calidad de vida, el rendimiento económico-social y la creación de nuevas oportunidades. De ahí que, los emprendimientos sociales son innovados mediante las políticas públicas enfocadas en el valor social que tienen. Por lo que, un emprendimiento representa el motor del modelo de la economía social, el cual, conlleva acciones gubernamentales para ser incentivar la creación de los mismos. Por eso, es necesario la creación de políticas públicas enfocadas en las PYMES, que promuevan el reconocimiento de estas nuevas organizaciones dentro del sistema económico-político, y con ellos la financiación de estos, dando cabida al mercado capital para la sociedad.

El modelo asociativo también es mecanismo de cooperación importante para el desarrollo local. La asociatividad permite alcanzar niveles de competitividad similares a los de empresas de mayor tamaño (Salazar et al., 2016). También permite incentivar las capacidades de las PYMES, fortaleciendo la competencia local (y exterior) en el mercado.

\section{Metodología}

Concatenadamente, en la investigación realizada se seleccionó la metodología cualitativa por cuanto esta, permite entender cómo los participantes de una investigación perciben los acontecimientos. La variedad de sus métodos, como son: la fenomenología, el interaccionismo simbólico, la teoría fundamentada, el estudio de caso, la hermenéutica, la etnografía, la historia de vida, la biografía y la historia temática, reflejan la perspectiva de aquel que vive el fenómeno (Hernández et al., 2014).

De ahí que, es importante hacer un recuento de la Economía Social y Solidaria (ESS) en América Latina y el mundo, para aterrizar en la perspectiva ecuatoriana y su particular incidencia en el desarrollo local, identificando las instituciones gubernamentales y no 
gubernamentales que intervienen en el mismo, para un posterior análisis de su progreso en el país y si su intención aplica dentro del mismo.

\section{Análisis}

Al ser relativamente "nuevo", el concepto de Economía Social y Solidaria (ESS), su aplicación en los países latinoamericanos es temprana, por ejemplo, en el caso de Colombia; se implementaron centros de desarrollo zonal en territorios pobres, con el apoyo de entidades integradoras sectoriales para el acompañamiento de los emprendimientos, desde las pequeñas hasta las grandes empresas, todo desde su administración municipal durante los años 2004 al 2007.

De la misma manera en el Ecuador, la Economía Social y Solidaria (ESS) se instauró a partir de la Constitución del 2008, en el artículo 283, que expresa que el sistema económico en el país a partir de entonces es social y solidario, reconoce además al ser humano como sujeto y fin; y propende a una relación dinámica y equilibrada entre sociedad, estado y mercado, en armonía con la naturaleza; y tiene por objetivo garantizar la producción y reproducción de las condiciones materiales e inmateriales que posibiliten el buen vivir. Pues, a través de este artículo en la constitución, la economía popular y solidaria, como sinónimo de la Economía Social y Solidaria en Ecuador, se dio a la población con escasos recursos la oportunidad de satisfacer sus necesidades humanas enfocadas en el buen vivir, a través de agentes institucionales que promovieran los procesos de producción, circulación, distribución y de consumo.

Desde la aprobación de la Economía Social y Solidaria, bajo el nombre de Economía Popular y Solidaria, nacieron instituciones como el Instituto Nacional de Economía Popular y Solidaria (IEPS) en el año 2009, la Corporación Nacional de Finanzas Populares y Solidarias (CONAFIPS) en el año 2011 y la Superintendencia de Economía Popular y Solidaria (SEPS) en el año 2012.

Todas estas instituciones se encargan de apoyar el desarrollo local mediante la asignación de recursos. Como mencionan Serrano (2019), el apoyo a los diferentes sectores ha consolidado la estabilidad laboral con la aplicación de medidas económicas que justifican el buen vivir justo y solidario.

Otras instituciones que también apoyan al desarrollo local son las cooperativas, las cuales, surgieron en Ecuador a fines del siglo XIX, cuando se conforman las primeras instituciones mutualistas de la mano de artesanos, industriales, obreros, comerciantes, empleados y patronos; instituciones caracterizadas por ser entidades gremiales y multifuncionales (Da Ros, 2007).

Asimismo, las cooperativas, pues, vendrían a ser instituciones creadas por diversas personas naturales o jurídicas. En el país, las cooperativas han apoyado 
significativamente al desarrollo, especialmente en lo que concierne a la economía local. Las cooperativas, entre sus distintos tipos, han apoyado al crecimiento de la producción agrícola, ganadera, transportista, obrero, artesanos, comerciantes, entre otros campos económicos.

De acuerdo con Poveda et al. (2017), entre los tipos de cooperativas se encuentran los siguientes:

Cooperativa de producción: Tiene como objetivo fomentar el desarrollo local mediante la fabricación de productos agrarios, industriales o artesanales usando los recursos dispuestos por los miembros de la cooperativa.

Cooperativa de ahorro y crédito: Bajo las leyes establecidas por cada país, este tipo de cooperativas suplen las necesidades financieras de las personas o terceros.

Cooperativa de comercialización: Brindan a las personas y socios diferentes tipos de mercadería que tengan libre comercio dentro del país.

Cooperativa de vivienda: Compra de bienes para la realización de obras, construcción y otras actividades de utilidad para los socios.

Cooperativa de servicios: Suplen las diferentes necesidades de los asociados o socios, como de alquiler de maquinaria agrícola, de transporte, o hasta de seguridad, entre otros.

Cooperativa de transportes: Brindan el servicio de transporte para las personas, $\mathrm{y}$ aseguran la buena calidad del mismo mediante préstamos internos.

Las cooperativas al igual que otras entidades se ocupan de llevar a cabo la creación de emprendimientos y empresas pequeñas, hechas por la sociedad, que desencadenan en el desarrollo económico local del país. Sin embargo, ¿funciona la Economía Social y Solidaria dentro del país? Pues, para responder a esa pregunta es necesario analizar las entidades e instituciones encargadas de llevar a cabo este modelo económico.

Bajo el nombre de EPS, las organizaciones de la misma están supervisadas por el organismo de supervisión y control SEPS. Tanto las organizaciones de la EPS como las de las FPS (Finanzas Populares y Solidarias), deben estar inscritas a la SEPS para poder funcionar en la vida jurídica.

Para la financiación de los emprendimientos, los emprendedores tienen que pasar por un riguroso trámite, en el que la primera vez en que los emprendimientos quieran ser parte de la EPS, después de inscritos deben esperar la carta de aceptación de la SEPS.

Una vez aceptado, y teniendo personería jurídica, la organización del emprendimiento en cuestión, tiene que pasar por la aprobación de la IEPS provincial, en el que, mediante un 
documento de presentación del proyecto a realizar, y con la capacitación correspondiente por parte del IEPS; el proyecto podría ser aprobado.

Si el emprendimiento presentado por la organización ha recibido la aceptación del IEPS provincial, se solicitan los servicios financieros de las organizaciones de las FPS como eslabón básico para su desarrollo. Son las organizaciones FPS de las localidades las que brindan el crédito para el financiamiento de los emprendimientos locales; pero, éstas (las entidades asociativas o solidarias, las cajas y bancos comunales, y las cajas de ahorro) no conceden el financiamiento si no reciben los recursos de la CONAFIPS no ocurre lo mismo con las cooperativas de ahorro y crédito, ya que cuentan con recursos propios y suficientes para conceder créditos a los emprendedores de las parroquias urbanas y rurales, sobre todo de las primeras (Auquilla et al., 2018).

Este largo, más que riguroso proceso, representa una gran limitante para las nuevas organizaciones con proyectos que requieren de una financiación de las FPS. Las cooperativas solo representan un sector del sistema de la Economía Social y Solidaria, en el país existen cuatro sectores; el sector comunitario, el sector asociativo, el sector micro empresarial y el sector cooperativo. El sector comunitario se conforma de grupos familiares, étnicos y culturales. El sector asociativo se integra por asociaciones de personas naturales. El sector micro empresarial se conforma de las Unidades de Economía Popular y Solidaria que se ocupan de llevar a cabo los proyectos de emprendimiento. Y el sector cooperativo que se conforma por las cooperativas (García et al., 2018).

\section{Resultados}

En Latinoamérica, la economía solidaria, se encuentra más relacionada con la economía popular (Chaves et al., 2013), debido a que se concibe como una corriente de transformación social alternativa, que le hace frente al modelo neoliberal económico, especialmente para mitigar la pobreza, el subdesarrollo de los países latinos y la justifica social (Singer, 1997). En divergencia, a los planteamientos europeos, que conciben a la economía solidaria perfectamente compatible con el estado y el mercado, la locución latinoamericana propone un proyecto global alternativo al capitalismo, identificándose como una fuerza de cambio social que le hace frente al movimiento neoliberal (Duque et al., 2021).

Pese a que la economía popular y solidaria (ESS) emerge en los países latinoamericanos como fuerza hegemónica yuxtapuesta al modelo tradicional económico, vemos que en la praxis esta teoría como panacea mágica para resolver asimetrías socio territoriales, presenta falencias.

Esto debido a que los agentes institucionales como el IEPS, la CONAFIPS, las Organizaciones del Sistema Financiero Popular y Solidario (OSFPS) y la 
Superintendencia de la Economía Popular y Solidaria (SEPS) encargados conducir el proceso de transformaciones, no han conseguido canalizar eficientemente dichos recursos hacia los territorios (Auquilla et al., 2018).

En el párrafo precedente, aunque se analiza las actividades que han realizado las entidades del Estado en relación a los recursos que deben asignarse de manera equitativa en el territorio nacional, mismos que no llegaron a tiempo, y que hoy por hoy no son distribuidos, debido a la falta de voluntad política, ineficiencia en el ejercicio profesional o simplemente por no cumplir con la extensa lista de requisitos previos a la obtención de créditos y más, por lo que podría inferirse que existe un escaso involucramiento por parte de la ciudadanía, en este último punto:

La participación ciudadana voluntaria y la colaboración con socios públicos, requiere que la economía solidaria sea comprendida como la forma de democratizar la economía y no como el resurgimiento de la filantropía. En síntesis, y según la definición planteada por Lipietz (citado en Cañedo et al., 2021), mientras la economía social responde a la pregunta “¿cómo hacerlo?”, en referencia a estatutos y reglas de funcionamiento, lo que definiría a la economía solidaria sería “¿en nombre de qué se hace?”, en referencia a valores, sentido de la acción y criterios de gestión (Duque et al., 2021, p.5).

Lo antes expuesto, se vincula a los principios que persiguen las organizaciones de la economía popular y solidaria, y del sector financiero popular y solidario, que son:

- La búsqueda del buen vivir y del bien común;

- La prelación del trabajo sobre el capital y de los intereses colectivos sobre los individuales;

- El comercio justo y consumo ético y responsable;

- La equidad de género;

- El respeto a la identidad cultural;

- La autogestión;

- La responsabilidad social y ambiental, la solidaridad y rendición de cuentas; $\mathrm{y}$,

- La distribución equitativa y solidaria de excedentes (Superintendencia de Economía Popular y Solidaria [SEPS], 2019).

De hecho, en una investigación realizada por Zhunio ( 2021), podemos observar la otra cara de la moneda en cuanto al comportamiento relacional de las personas que integran el sector financiero, en donde las actividades de control por parte de los organismos estatales desde el período 2012 hasta el cierre del 2019, correspondió al $40 \%$, cifra que representa el porcentaje de organizaciones disueltas por manejo 
inadecuado que vulnera el fondo de los socios, y patrimonio de las entidades, registrándose para ese entonces 295 procesos penales en el sector.

Acorde a lo expuesto, es necesario en posteriores investigaciones profundizar el tema, porque cómo podemos visualizar, no sólo se trata de la falta de eficiencia del sector estatal, sino también de ciudadanos que buscando lucrar rápidamente, y para esto conforman cooperativas de ahorro y crédito para ocultar otro tipo de actividades ilícitas.

Otro de los puntos esbozados en el desarrollo del artículo es el tema de las capacitaciones por parte de las entidades del sector público, y en los informes respectivos de rendición de cuentas vemos como efectivamente:

En el año 2019, se capacitaron a nivel nacional a 9830 personas, representantes de un total de 1349 entidades, organizaciones, cajas de ahorro e instituciones privadas. Las capacitaciones realizadas respondieron principalmente a temáticas relacionadas con normativa, fortalecimiento para las entidades y organizaciones contraladas, así como formación de los socios (SEPS, 2020).

El tipo de capacitaciones que se impartieron estuvieron enfocadas en fortalecer el desempeño del sector de la EPS, minimizar hallazgos en procesos de supervisión, optimización de recursos y el aprovechamiento de economías de escala (SEPS, 2021, p.31).

En comparación con el año 2020, se capacitaron a nivel nacional a 11.911 personas, representantes de un total de 1.726 entidades financieras, organizaciones de la economía popular y solidaria, academia e instituciones públicas como privadas. Las capacitaciones realizadas respondieron principalmente a temáticas relacionadas con normativa, fortalecimiento para las entidades financieras y organizaciones de la economía popular y solidaria contraladas en respuesta a la pandemia de la COVID19, así como formación de los socios (SEPS, 2021, p.51).

Finalmente, no fue representativo el número de capacitaciones para el año 2020, ya que por efectos de la pandemia se tuvo que recurrir al chat institucional como recurso para solventar las necesidades imperantes del sector financiero, lo que nos lleva a otro punto de análisis para futuras pesquisas, y es el papel que juega la tecnología al momento de buscar soluciones eficaces a problemas recurrentes, ahora bien, aún queda mucha coordinación por parte del sector gubernamental en pro de articular la economía popular y solidaria con el sector económico tradicional sin fragmentarlo. 


\section{Conclusiones}

- La Economía Social y Solidaria en el Ecuador al estar enmarcadas en un marco legal e institucional, respalda iniciativas de emprendimiento social que promuevan la resolución de problemas sociales, combinando conceptos tales como: rentabilidad y misión social, concertando así el valor económico y social de emprendimientos individuales y colectivos, en procura de mejorar las condiciones socioeconómicas de la población más vulnerable.

- Los principios de reciprocidad, solidaridad y cooperación que presiden la economía popular y solidaria del país, son la característica principal que lo diferencian del modelo económico tradicional de mercado, por cuanto, no persigue como fin último el redito económico, al contrario, al ser en esencia de índole social, esta promueve el dinamismo mediante la generación de empleos de calidad, contribuyendo al desarrollo social y económico.

- La creación de políticas públicas encaminadas a actividades de innovación y tecnología son necesaria para contribuir al desarrollo y crecimiento económico de la nación, porque los recursos de los cuales disponen los distintos organismos gubernamentales inmersos en la Economía Social y Solidaria no son distribuidos de manera equitativa en el territorio nacional, y en la mayoría de los casos son asignados a emprendimientos meramente económicos.

- El desarrollo local en la parte rural del país es incipiente, debido a que las organizaciones gubernamentales que se crearon con el fin de brindar apoyo, asesoría y capacitación no han realizado lo propio, obstaculizando el desarrollo de actividades económicas, ejemplo: Por falta de créditos financieros, entre otros.

\section{Referencias Bibliográficas}

Auquilla, L., Auquilla, Á., \& Ordoñez, E. (2018). La economía popular y solidaria y las finanzas populares y solidarias en Ecuador. Killkana Sociales, 2(3), 17-24.

Cañedo, R., Barragán, M., \& Esparza, J. (2021). La construcción de redes de entidades de la Economía Social y Solidaria desde lo local. Sobre México Temas De Economía, 45-75.

Coraggio, J. L. (2011). Economía Social y Solidaria. El trabajo antes que el capital. Quito: Abya-Yala.

Da Ros, G. (2007). El movimiento cooperativo en el Ecuador. Visión histórica, situación actual y perspectivas. Economía Pública, Social y Cooperativa, 249-284. 
Duque, P., Meza, O., Giraldo, D., \& Barreto, K. (2021). Economía Social y Economía Solidaria: un análisis bibliométrico y revisión de literatura. Revesco (138) 2021: 1-251ARTÍCULOSREVESCO. Revista de Estudios Cooperativos (138). Doi: https://doi.org/10.5209/reve.75566

García, K., Prado, E., Salazar, R., \& Mendoza, J. (2018). Cooperativas de Ahorro y Crédito del Ecuador y su incidencia en la conformación del Capital Social (20122016). Espacios, 39(28), 32.

Hernández, R., Fernández, C., \& Baptista, P. (2014). Metodología de la investigación. México: McGraw-Hill.

Poveda, G., Erazo, E., \& Neira, G. (2017). Importancia de las cooperativas en el Ecuador al margen de la economía popular y solidaria. Observatorio de la Economía Latinoamericana, 6-8.

Salazar, F., González, C., \& Taranto, F. (2016). El aporte del marketing en la economía popular y solidaria como modelo de desarrollo emergente en el Ecuador. Revista Publicando, 3(8), 467-468.

Serrano, L. (2019). Economía Popular y Solidaria: Base para el Desarrollo Asociativo y Buen Vivir. Espacios, 40(14), 25.

Superintendencia de Economía Popular y Solidaria [SEPS]. (2019). Rendición de cuentas 2019.

https://www.seps.gob.ec/documents/20181/978600/Informe+Rendici\%C3\%B3n +de+Cuentas+SEPS+2019.pdf/1a2addf2-7e6e-417e-b7cd-

$57 \mathrm{f} 6 \mathrm{~b} 7 \mathrm{~d} 43 \mathrm{a} 2 \mathrm{~b}$ ?version $=1.1$

Superintendencia de Economía Popular y Solidaria [SEPS]. (2020). Rendición de cuentas 2020.

https://www.seps.gob.ec/documents/20181/1026889/Rendici\%C3\%B3n+Cuenta s+2020.pdf/4cc3c161-e0eb-482d-bd84-a8e6edd5bdda?version=1.0

Superintendencia de Economía Popular y Solidaria [SEPS]. (2021). Conoce que es la Economía Popular y Solidaria (EPS). https://www.seps.gob.ec/noticia?conocela-eps

Tapia, M., \& Alvarado, F. (2019). Principios básicos de la Economía Social y Solidaria en el marco de la satisfacción de las necesidades humanas colectivas. Dominio de las ciencias, 5(3), 731-740. 
Villacrés, R., Pomaquero, J., \& López, J. (2018). Economía popular y solidaria: su evolución en el contexto ecuatoriano. Contribuciones a las Ciencias Sociales, 34.

Zhunio, G. (2021). "La economía popular y solidaria: Un modelo para el desarrollo". http://repositorio.ucsg.edu.ec/bitstream/3317/15873/1/T-UCSG-POS-MFEE237.pdf

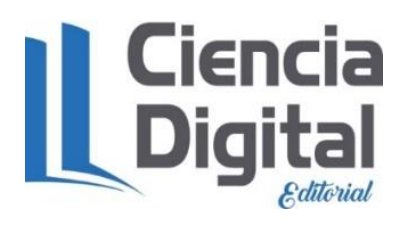


El artículo que se publica es de exclusiva responsabilidad de los autores y no necesariamente reflejan el pensamiento de la Revista Alfa Publicaciones.

\section{Ciencia}

El artículo queda en propiedad de la revista y, por tanto, su publicación parcial y/o total en otro medio tiene que ser autorizado por el director de la Revista Alfa Publicaciones.
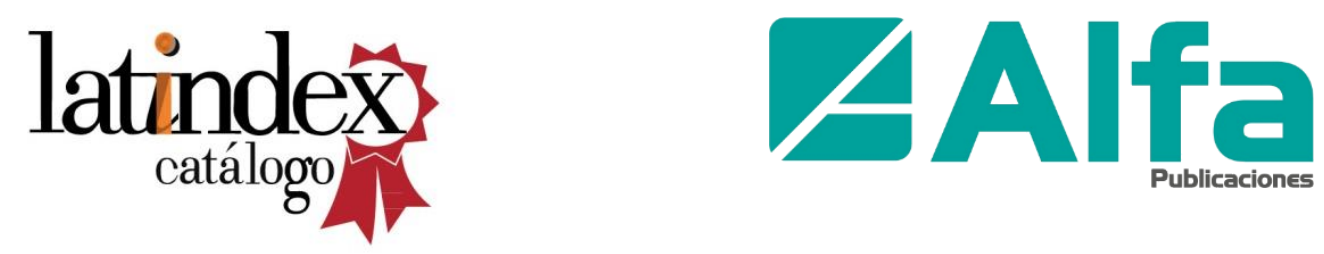

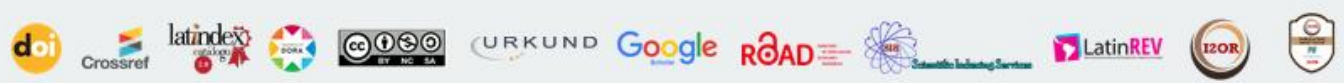
ESJI $=$ REDIB 